\title{
Desenvolvimento de Cultivares de Alface em Sucessão a Leguminosas
}

Gesiane R. Guimarãesa, Faber S. Pereira, Alexandre M. E. Oliveira, Ednaldo C. Rocha \& Roberli R. Guimaraes

Este trabalho foi realizado na Universidade Estadual de Goiás, Unidade de Ipameri, de agosto a setembro de 2012. O objetivo foi avaliar o desenvolvimento de quatro cultivares de alface em sucessão a leguminosas. O delineamento experimental foi o de blocos casualizados, com cinco repetições. A avaliação da produção foi pelo número de folhas e peso fresco de seis plantas úteis por tratamento, totalizando 30 plantas por tratamento. O plantio de alface, sucedendo o cultivo de leguminosas, proporcionou melhor desenvolvimento às cultivares Delícia, Grandes Lagos e Manteiga, as quais mais se destacaram em quantidade de folhas e peso fresco.

Palavras-chaves: Adubação verde; Cultivo orgânico; Conservação do solo.

This study was conducted at the State University of Goiás, UnU Ipameri, AugustSeptember 2012. The objective was to evaluate the development of four lettuce cultivars grown after legumes. The experimental design was a randomized block with five replications. The evaluation of the production was the number of leaves and fresh weight of six plants per treatment, totaling 30 plants per treatment. The planting of succeeding lettuce crop legume cultivars to enhanced growth Delight, Great Lakes and Butter, which stood out in number of leaves and fresh weight.

Keywords: Green manure; Organic farming; Soil conservation. 


\section{Introdução}

A alface é uma das hortaliças mais cultivadas em todo o mundo. É consumida de forma in natura, constitui boa fonte de vitaminas e sais minerais e é recomendada para dietas alimentares ricas em fibras ${ }^{1}$. O cultivo orgânico dessa hortaliça, além de ecologicamente correto, gera um produto com melhores características sensoriais e de maior vida útil pós-colheita, em comparação aos sistemas convencionais ${ }^{2}$.

As cultivares de alface disponíveis, atualmente são de coloração verde, em sua maioria, existindo também cultivares com folhas arroxeadas. Os tipos de cultivares de alface existentes são: Repolhuda-Manteiga, RepolhudaCrespa (Americana), Solta-Lisa, Solta-Crespa, Mimosa e Romana ${ }^{3}$.

A cultura da alface não conta com uma rede de ensaios de competições de cultivares que envolva locais, épocas e anos de plantio diversificados, o que é diferente do que ocorre com outras culturas como a batata, o milho e o feijão. Essa deficiência leva o produtor a utilizar cultivares recomendadas pelas empresas produtoras de sementes e que podem não se adaptarem a uma ampla faixa de ambientes, fato esse de grande interesse ao produtor que deseja desenvolver sua produção. Essa situação leva a dificuldades na obtenção de melhores produtividades, considerando as diferentes estações climáticas em que a alface é cultivada, haja vista que as cultivares interagem com o ambiente, mesmo que esse ambiente seja protegido ${ }^{4}$.

$\mathrm{O}$ uso da adubação verde nas unidades de produção orgânica é uma estratégia importante com elevado potencial de impacto na produtividade das culturas e na conservação do solo. O uso de espécies de leguminosas, notadamente em áreas passíveis de pousio, tem sido preconizado como alternativa interessante para o suprimento de nitrogênio às culturas $^{5}$. A adubação verde acrescenta nitrogênio e outros nutrientes ao agroecossistema; proporciona cobertura ao solo; reduz riscos de erosão; atenua a competição das plantas espontâneas com as culturas e contribui para a biodiversidade funcional nas unidades de produção ${ }^{6}$.

Uma das alternativas para viabilizar os sistemas de produção é a adubação verde, que consiste no cultivo de diferentes culturas com propriedades que contribuem com melhorias nas condições do solo, adequando-o para o plantio de culturas de interesse comercial, como na produção de hortaliças. As contribuições são consideráveis à viabilidade econômica e sustentabilidade dos agroecossistemas, pelo aporte de quantidades expressivas de $\mathrm{N}$ ao sistema soloplanta, reduzindo assim, a necessidade de $\mathrm{N}$ sintético. Além do aporte de $\mathrm{N}$ e da diminuição da erosão, os adubos verdes desempenham papel fundamental na ciclagem de nutrientes, tanto dos aplicados por meio dos fertilizantes minerais e não aproveitados pelas culturas, quanto daqueles provenientes da mineralização da matéria orgânica do solo e do próprio material vegetal ${ }^{7}$.

As espécies mais utilizadas para a adubação verde são as leguminosas, pelo fato de elas terem a capacidade de fixar nitrogênio por meio da simbiose de bactérias em seus sistemas radiculares ${ }^{8}$. Nesse contexto, Linhares e colaboradores ${ }^{9}$, afirmam que quando se adiciona um adubo verde ao solo, este trará benefícios não só ao primeiro cultivo, mas também a cultivos sucessivos que caracterizase pela viabilidade no emprego desse insumo. Assim, o objetivo deste trabalho foi avaliar o desenvolvimento de quatro cultivares de alface em sucessão a leguminosas.

\section{Material e Métodos}

O estudo foi conduzido na área experimental da Universidade Estadual de Goiás - Unidade de Ipameri, sudeste de Goiás (Coordenadas geográficas: 1743’02,4” S / 4808'36,7” O).

As leguminosas foram semeadas em novembro de 2011, cortadas e incorporadas em agosto de 2012, vinte e cinco dias antes do transplantio. Foram utilizadas as seguintes leguminosas: Crotalária (Crotalaria juncea L.e C. spectabilis R.); Feijão de porco (Canavalia ensiformis (L.); Mucuna preta (Stizolobium aterrinnum PT.) e Mucuna verde e cinza (Stizolobium spp.); Feijão guandu (Cajanus cajans (L.); Feijão rajado (Phaseolus vulgaris L.) e Estilozante campo grande (Stylosantes capitata V. (80\%) e S. Macrocephala FC. (20\%), sendo cultivadas no Sistema Integrado de Produção Agroecológica.

A semeadura da alface de cultivares (Delícia, Grandes Lagos e Manteiga), nas bandejas de isopor, contendo 200 células, foi realizada no dia 30 de agosto de 2012 e o transplantio para os canteiros ocorreu no dia 20 de setembro de 2012 (Figura 1). Essas mudas foram produzidas em casa de vegetação, com substrato comercial, constituído de subsolo argiloso, esterco bovino curtido e vermicomposto e irrigadas diariamente.

Foram feitos canteiros que mediam 1,0 m de largura $\mathrm{x} 1,0 \mathrm{~m}$ de comprimento $\mathrm{x} 0,2 \mathrm{~m}$ de altura, nos quais $\mathrm{o}$ 


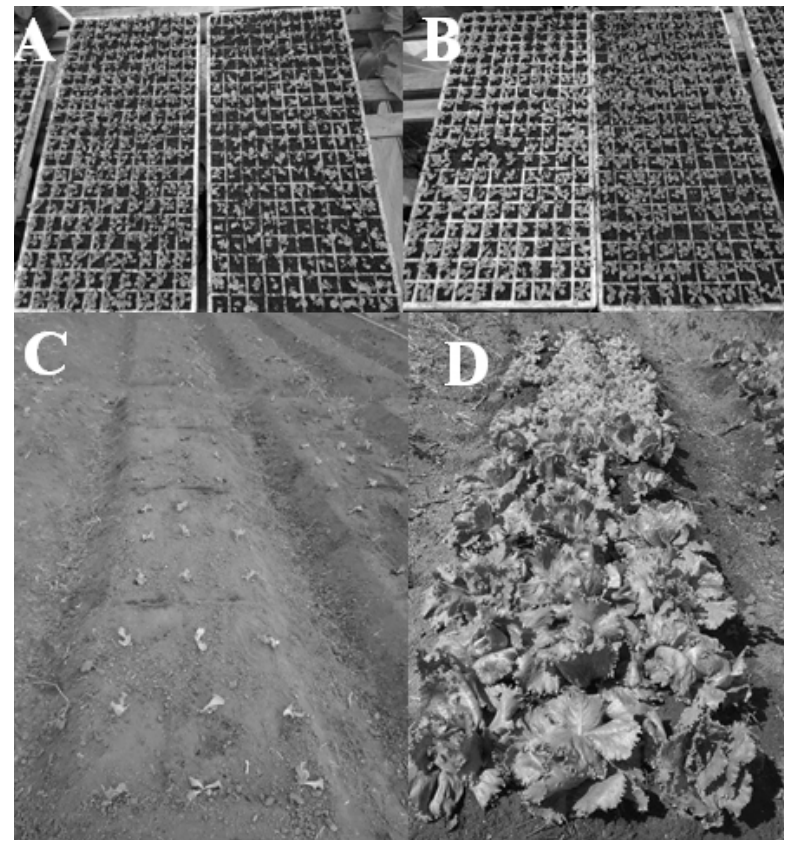

Figura 1. Semeadura das cultivares em bandejas de isopor (A e B), transplantio para os canteiros (C) e cultivares após 30 dias de transplantio (D).

espaçamento utilizado no plantio foi de $0,30 \times 0,30 \mathrm{~m}$, totalizando 9 plantas por $\mathrm{m} 2$, referente à área de cada parcela. O delineamento experimental utilizado foi o de blocos casualizados com cinco repetições, utilizando quatro cultivares de alface: Marisa (Repolhuda crespa), Grandes lagos (Americana), Delícia (Americana) e Boston branca (Manteiga).

As adubações foram realizadas três dias antes do transplantio, incorporando adubo bovino (esterco). As adubações de cobertura com esterco bovino foram realizadas no $7^{\circ}$ e $22^{\circ}$ dias, após o transplantio (DAT). Três capinas manuais foram necessárias para a remoção das plantas daninhas dos canteiros e a irrigação foi realizada manualmente duas vezes ao dia com o auxílio de regadores. A colheita ocorreu aos 30 dias após o transplantio, sendo as alfaces cortadas rentes ao solo, submetidas a uma prélimpeza, em que as folhas baixeiras, senescentes ou lesionadas foram descartadas.

A avaliação do desenvolvimento das cultivares foi feita por meio do número de folhas e do peso fresco das plantas presentes na parcela útil, a qual era constituída por seis plantas coletadas por parcela, totalizando 30 plantas por tratamento. Os dados foram submetidos à análise de variância e, nos casos em que o teste $\mathrm{F}$ foi significativo, realizou-se o teste de Scott Knott para comparação múltipla das médias dos tratamentos (ambos com $\mathrm{p}<0,05$ ). Essas análises estatísticas foram conduzidas, utilizando-se o software SISVAR $5.3^{10}$.

\section{Resultados e Discussão}

A colheita da alface ocorreu aos 30 dias após o transplantio (DAT). Os resultados das análises estão sintetizados na Tabela 1. Nota-se que houve diferença significativa $(p>0,001)$ para as duas variáveis avaliadas, massa fresca e quantidade de folhas.

A cultivar Delícia foi a que apresentou a maior média de massa fresca, pesando $243 \mathrm{~g}$, a qual foi seguida pela cultivar Manteiga (232 g), pela Marisa (193 g) e pela Grandes Lagos (143 g), sendo detectada diferença significativa pelo teste de Scott Knott entre todas as cultivares (Tabela 2).

A quantidade média de folhas da cultivar Delícia foi 43,6, valor estatisticamente superior às médias de folhas das demais cultivares. Manteiga, Marisa e Grandes Lagos foram estatisticamente semelhantes, com médias de 35,8, 31,6 e 28,6 folhas, respectivamente. Resultados de número de folhas relativamente semelhantes foram obtidos por Rezende e colaboradores ${ }^{11}$ em Brasília-DF, os quais encontraram média de 26,5 folhas por planta para a cultivar Grandes lagos e 23,1 folhas por planta para a cultivar Americana, ambas produzidas em sucessão a leguminosas.

Tabela 1. Resumo da análise de variância para a massa fresca e quantidade de folhas de quatro cultivares de alface.

\begin{tabular}{|c|c|c|c|}
\hline \multirow{2}{*}{$\begin{array}{l}\text { Fonte de } \\
\text { variação }\end{array}$} & \multirow[b]{2}{*}{ GL } & \multicolumn{2}{|c|}{ Quadrados médios } \\
\hline & & $\begin{array}{c}\text { Massa fresca } \\
\text { (g) }\end{array}$ & $\begin{array}{l}\text { Quantidade } \\
\text { de folhas }\end{array}$ \\
\hline $\begin{array}{l}\text { Cultivares de } \\
\text { alface }\end{array}$ & 3 & $10.213,87 * *$ & $211,80 * *$ \\
\hline Blocos & 4 & 186,38 & 19,70 \\
\hline Resíduo & 12 & 45,74 & 21,13 \\
\hline $\begin{array}{l}\text { Coeficiente de } \\
\text { variação }\end{array}$ & & $3,33 \%$ & $13,17 \%$ \\
\hline
\end{tabular}

** significativo a $1 \%$ de probabilidade pelo teste $\mathrm{F}$. 
Tabela 2. Resultado do teste de médias para a massa fresca e quantidade de folhas de quatro cultivares de alface.

\begin{tabular}{|c|c|c|}
\hline \multirow{2}{*}{ Fonte de variação } & \multicolumn{2}{|c|}{ Médias } \\
\cline { 2 - 3 } & Massa fresca (g) & $\begin{array}{c}\text { Quantidade de } \\
\text { folhas }\end{array}$ \\
\hline Delícia & $243 \mathrm{a}$ & $43,6 \mathrm{a}$ \\
\hline Manteiga & $232 \mathrm{~b}$ & $35,8 \mathrm{~b}$ \\
\hline Marisa & $193 \mathrm{c}$ & $31,6 \mathrm{~b}$ \\
\hline Grandes lagos & $143 \mathrm{~d}$ & $28,6 \mathrm{~b}$ \\
\hline
\end{tabular}

Médias seguidas por uma mesma letra dentro de cada coluna não diferem entre si, a $5 \%$ de probabilidade, pelo teste de Scott Knott.

Bueno $^{12}$ encontrou efeito significativo para número de folhas com resposta linear crescente em relação às doses de nitrogênio. Em alface, a maior quantidade de folhas por planta resulta, em geral, numa maior área foliar, maior massa fresca e, consequentemente, maior produtividade.

A absorção dos nutrientes, advindos da mineralização dos adubos verdes, pelas hortaliças depende, em grande parte, da sincronia entre a decomposição, mineralização dos resíduos vegetais e a época de maior exigência nutricional da cultura. De acordo com Diniz ${ }^{13}, 24$ dias após a incorporação dos resíduos de Mucuna cinza (Stizolobium cinereum PT.), $50 \%$ do nitrogênio presente no adubo verde já havia sido liberado. A maior taxa de absorção e acúmulo de nutrientes do repolho ocorre entre 60 e 70 dias após o transplante. Assim, no presente estudo, possivelmente, não houve sincronia entre a máxima liberação de nutrientes dos adubos verdes e a época de maior exigência nutricional da alface, pois o transplantio das mudas ocorreu aproximadamente 40 dias após a incorporação das leguminosas.

\section{Conclusão}

Em sucessão ao cultivo de leguminosas, a cultivar delícia apresentou o melhor desenvolvimento em termos de massa fresca e quantidade de folhas. As cultivares Manteiga e Marisa obtiveram desempenho intermediário para a variável massa fresca. Para a quantidade média de folhas, as cultivares Manteiga, Marisa e Grandes Lagos apresentaram desenvolvimento semelhante.

\section{Referências}

1. Araújo, W. F.; Kelly, Sousa T. S.; Viana, T. V. A.; Azevedo M. B.; Barros, M. M.; Marcolino, E.; Revista Agro@mbiente On-line 2011, 5, 12.

2. Almeida, M. M. T. B.; Lixa, A. T.; Silva, E. E.; Azevedo, P. H. S.; De-Polli, H.; Ribeiro, R. L. D.; Pesq. Agropec. Bras. 2008, 43, 675.

3. Taveira, A. T.; Martins, L. B.; Dal Poggetto, M. T.; Martins, M. E.; Souza Júnior, M. N. De; Vieira, T. A.; Vallone, H. S.; II Seminário Iniciação Científica-IFTM, Campus Uberaba, MG. 20 de outubro de 2009.

4. Tosta, M. S.; Borges, F. S. P.; Reis, L. L.; Tosta, J. S.; Mendonça. V.; Tosta, P. A. F.; Agropecuária Científica no Semi-Árido 2009, 5, 30.

5. Silva, E. E.; Polli H; Guerra, J. G. M.; Aguiar-Menezes, E. L.; Resende, A. L. S.; Oliveira, F. L.; Ribeiro, R. L. D.; Hortic. Bras. 2011, 29, 57.

6. Oliveira, F. L.; Ribas, R. G. T.; Junqueira, R. M.; Padovan, M. P.; Guerra, J. G. M.; Almeida, D. L.; Ribeiro, R. L. D.; Agronomia 2003, 37, 60.

7. Perin, A.; Guerra, J. G.; Texeira, M. G.; Pesq. Agropec. Bras. 2003, $38,791$.

8. Favero, C.; Jucksch, I; Alvarenga, R. C.; Costa, L. M.; Revista Brasileira Ciência do Solo. 2000, 24, 171.

9. Linhares, P. C. F.; Fernandes, I. T. D.; Silva, M. L.; Pereira, M. F. S.; Santos, A. P.; Revista Verde 2010, 5, 168.

10. FERREIRA, D.F. R.Sympos. 2008, 6, 36 .

11. Resende, F. V.; Saminêz, T. C. O.; Vidal, M. C.; Sousa, R. B.; Clemente, F. M. V.; Cultivo de Alface em Sistema Orgânico de Produção. Circular Técnica 56. Embrapa: Brasília, 2007.

12. Bueno, C. R.; Adubação nitrogenada em cobertura via fertirrigação por gotejamento para a alface americana em ambiente protegido. Dissertação (Mestrado em Agronomia). Universidade Federal de Lavras: Lavras. 1998.

13. Diniz E. R.; Influência da época de incorporação de adubo verde na produção de brócolis cultivado organicamente. Dissertação (Mestrado e Fitotecnia). Universidade Federal de Viçosa: Viçosa. 2004.

Gesiane R. Guimarãesa*, Faber S. Pereira, Alexandre M. E. Oliveira, Ednaldo C. Rocha \& Roberli R.

\section{Guimaraes}

Universidade Estadual de Goiás, Rodovia: GO 330, km 241, Anel Viário s/n, Ipameri-GO, CEP: 75780-000.

*gesianerib.guimaraes@gmail.com 